\title{
Problem Exploration with Bias Breaking Ideation for Maritime Emissions Reduction
}

\author{
Sixiong PENG ${ }^{\mathrm{a}, 1}$, Lorena PELEGRIN ${ }^{\mathrm{b}}$, Patricia ARNAL LUNA ${ }^{\mathrm{b}}$, Hideyuki HORII ${ }^{\mathrm{a}}$ \\ and Bryan R. MOSER ${ }^{\mathrm{a}, \mathrm{b}}$ \\ ${ }^{a}$ University of Tokyo, Japan \\ ${ }^{b}$ Massachusetts Institute of Technology, USA
}

\begin{abstract}
This papers presents a quasi-experiment on the characteristics of innovation teams during the early stages of a project, with an emphasis on number and categries of ideas generate with quality throgh a bias-breaking ideation exercise. This quasi-experiment raised several interesing questions on the combination of individual and collective ideation and its relationshop to more innovative outcomes (e.g., quantity of ideas, originality, transformation potential) than solely individual or group thought. Is there an optimal combination of individual and group work that fosters better outcomes? Further, the timing, quantity and quality of communication between team members is also expected to influence the outcomes of ideation processes, and constitutes another focus of this research. What are the characteristics of communication conducive to innovation?
\end{abstract}

Keywords. Project Teamwork, Innovation, Ideation Workshops, Collective Intelligence, Bias Breaking

\section{Introduction}

Complex challenges require significant collaboration and flexibility to consider new approaches and combinations as compared to conventional solutions. Various techniques are used to promote innovative thinking as such. During these ideation methods there are both invidivual and collective stages of idea generation, evaluation, and selection.

A teamwork experiment was conducted to challenge participants in teams to ideate about new challenges in ths shipping industry practicing the bias breaking methodology. The challenge addressed the maritime shipping industry's imperative to reduce $\mathrm{CO} 2$ emissions, ultimately achieving $0 \%$ Emission Shipping by 2050 . Multidisciplinary teams of 3 to 5 members reviewed conventional problem and solution spaces in order to identify established biases in the domain. Facts in terms of technology, institutional policies, societal requests, or social constructs were identified, and associated assumptions and beliefs distilled. Then, both individuals and teams were prompted to generate, evaluate, and select ideas that break these identified biases.

In the pilot experiment, teams were encouraged to ideate purely on the basis of creativity (originality, potential for disruption, surprise), without specific consideration of feasibility. The team members used a software platform in order to identify and share facts and ideas (thoughts) with one another in the form of digital sticky notes and links

\footnotetext{
${ }^{1}$ Corresponding Author, Email: sbo@ischool.or.jp.
} 
(relations) between thoughts. The software collected data of the time and changes on the ideation canvases by each team. Further instrumentation included audio recording and post-surveys.

\section{Background and Purpose}

For addressing challenges with many stakeholders, diverse needs, capabiliies and various technologies, this research shares the view of engineering projects as sociotechnical systems. The complexity of problem solving is both technical and social. In combination the collective capability of teams comes from their awareness, attention, generation of ideas, exploration of a solution tradespace. The teams exhibit a collective capability to explore options balancing desirability and feasibilty [1].

It is well know that for complex problem-solving, teams struggle given the high dimensionality of decisions with potential tradespaces that are huge. It is not be practically possible to evaluate all options. Various uncertainties cloud the decisions. In addition to solution complexity and uncertainty, this paper deals with a third common barrier: bias. Bias is defined as "an inclination of temperament or outlook, especially: a personal and sometimes unreasoned judgment." [2] "Bias, or design fixation, is said to inhibit human creativity" [3][4].

Numerous researchers have studied the effect of explicitly realizing bias to avoid it [5][6][7]. However, the effect is not consistently characterizes amongst these studies. Marsh et al. [6] reported that participants failed to edit out their prior knowledge even if they were instructed to do so. On the other hand, however, Chrysilou and Weisberg found that instructions to avoid use of example designs provided to the participants diminished design fixation [5].

In addition, research has tended to study the effect in design tasks in an experimental situation, and whether these insights can be applied to more general situations of creating new ideas is still doubtful [6][8].

This research aims to investigate the result of innovation workshops where participants created a novel business idea and obtain practical implication for introducing avoiding bias to broader situation.

\section{Research Approach}

The general research approach we have followed deployes digital models and communications tools to express a challenge and gather the exploration and response of teams to a challenge. These instrument teamwork experiements include classic methods for setting up an experiment with a diverse set of teams, survey-based understanding of the context, demographics, and outcomes, and ethnography for participant-observer contribution to the interpretation of activity in the workshops. General desription; field guide reference [9][10].

These workshop have been applied to teamwork for complex problem-solving both in very early problem seeking and ideations sessions [11] and also in the downstream team-based planning and implementation of solutions [12][13][14][15].

A "Bias breaking" workshop was held in a class of System Design Management course of Massachusetts Institute of Technology (MITsdm). Twenty-two teams of 3 to 5 people joined the workshop. All of them are student have at least three and an average 
of 10 years of professional career experience in engineering systems fields. The goal of the workshop is to create an idea to achieve Zero Emission Shipping, which does not emit any $\mathrm{CO} 2$, in the maritime shipping industry. The International Maritime Organization (IMO), has recently set very strong regulatory targets for the reduction of emissions over the next century [16][17]. The workshop process is designed as follows to make participants explicitly recognize biases and then try to avoid these biases during generation of new technology and business strategies for the maritime industry.

\section{Workshop Steps}

The workshop followed five basic steps as listed below.

\section{Listing conditions in conventional problem and solution spaces.}

Participants firstly listened to a presentation by people who had engaged in a project to create an idea to achieve Zero Emission Shipping. The presentation mainly included the background of the project and the conditions for creating solutions. The presentation slide is attached in Appendix. Based on this presentation, participants listed up and categorized conditions such as facts, rules, common sense, and beliefs for achieving Zero Emission Shipping. This would be a candidate of bias when creating an idea. This process was supposed to be conducted as a group work.

\section{Clarifying the reason why the condition should be true.}

Next, participants were instructed to think about the reason why the conditions they listed in the first step should be true. They thought about and wrote down the reason for as many conditions as possible. This process was also conducted as group work.

\section{Identifying which conditions are not necessarily true.}

Then the next step was to identify conditions which are not necessarily true based on the result of the step 1 and 2 . This process was conducted individually. Each member in a team doubted conditions without discussing with each other.

\section{Creating an idea to achieve Zero Emission Shipping without the identified conditions.}

The fourth step was to create an idea to achieve Zero Emission Shipping. The step 3 and 4 were practically conducted seamlessly. After identifying a condition which might not be true, participants kept on thinking individually of possible ideas enabled by an absence of that condition.

\section{Idea sharing and evaluation}

The last step was sharing and evaluating ideas. Each member shared his or her best idea to the team, and evaluated that idea as a group. At last, the team chose the best idea as a team and presented it to other teams. 


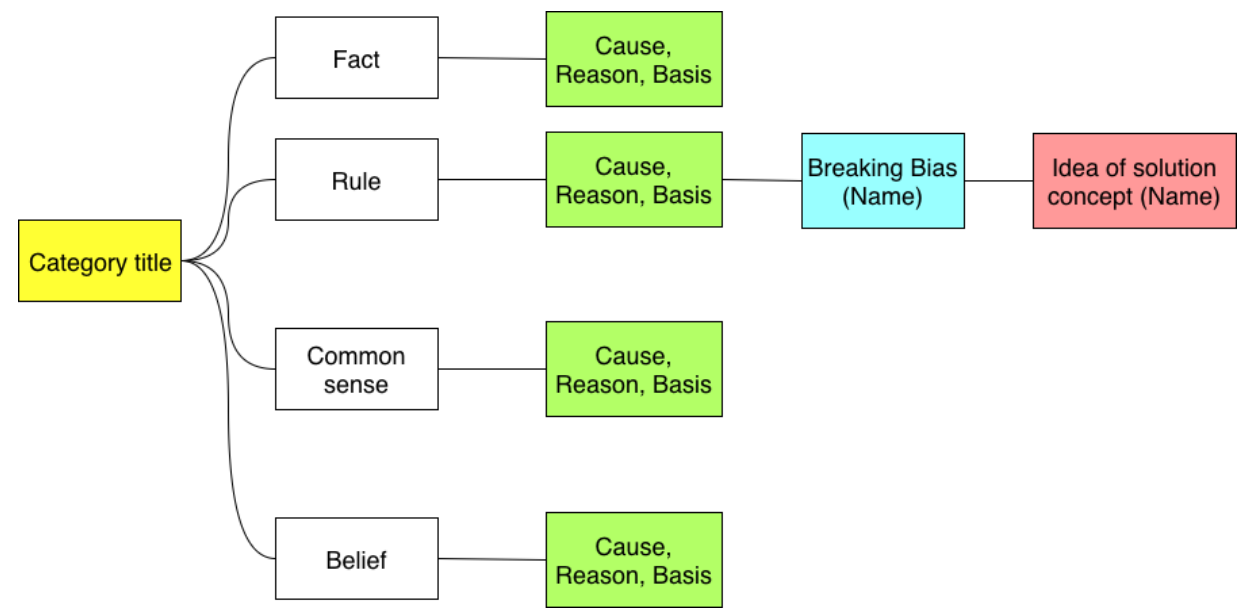

Figure 1. Ideation Notes for Bias Breaking Workshop.

\section{Evaluation of Performance}

For measuring the performance of groups, rather than the final ideas, the "Breaking Bias" notes, which were created in the step 3 were evaluated. The main reason for evaluating these notes is the possibility to evaluate them more objectively than final ideas; the evaluation of ideas is difficult and outcomes may be driven by other intermediate factors. On the other hand, Breaking Bias notes have clearer standards of evaluation on the basis of theoretical background of the breaking bias method. In addition, evaluation of the final idea has a risk to falsely rate seemingly good ideas which were created unrelated to breaking bias as a good idea. To distinguish a successful team correctly in this reserach, only ideas which was created by breaking bias were evaluated.

Theoretically, good Bias Breaking notes should state that a condition which is implicitly held by people and limits solution space is reasonably false. Hence Bias Breaking notes fulfilling this would be a good Bias Breaking. Looking into the detail of notes which were created in the workshop, there are four types of bad Bias Breaking notes. The first type does not state that a condition is false in the first place. This includes a note which rather supports a condition, or is simply not understandable.

The second type is that a statement lacks reliability. This type includes a note which points out the possibility that the statement may be false, such as "technological advancement might make this condition false." This type can lower feasibility of a final idea because the doubted condition might still be true.

The third type is that the way a note doubts a condition has already been already common. For example, even if a condition that ships should use oil as main energy source had been doubted by mentioning a renewable energy, this might not create new idea because utilizing a renewable energy has been considered widely. Thus, this type can lower novelty of a final idea. The fourth type is that a doubted condition might not limit solution space in the first place. For example, the fact that $\mathrm{CO} 2$ emissions will increase by $50 \%$ to $250 \%$ in 2050 may not limit an idea to reduce CO2. This type is mainly the reason why Zero Emission Ship is needed. Doubting this kind of point will not lead to an appropriate idea to achieve Zero Emission Ship. 
Therefore, a Bias Breaking note will be rated as bad if it can be categorized into one or more of the four types. The rest of the notes will be good notes.

Although the criteria are set, it sometimes requires relatively subjective judgement. Hence all the Bias Breaking notes were evaluated by at least two people. Four people joined the evaluation in total. One member evaluated all the idea and each of three other members evaluated one-third of the ideas. If the evaluation did not match, all of the four members discussed together and decided the evaluation of that note.

Through this evaluation of Bias Breaking notes, the number of good notes was identified for each team, which serves as an indicator of a performance of the group. Following analyses were conducted to explain the difference in performance of each team.

\section{Categorization of Workshop Topics}

Since effective Bias Breaking notes are defined to point out that a certain condition is false, whether a team could list up a condition which might be false is important. Thus, the number or the type of notes about conditions might correlate with the performance of each team. For verifying this hypothesis, the number of white notes created in the workshop was counted for each team. Also, all the notes about conditions were categorized into seven categories and twenty-seven subcategories. These categories were decided by grouping notes which share similar topics multiple times. Then the number of notes by each category was compared with the team performance.

\section{Workshop Results}

\section{Workshop Implementation}

Among twenty-two teams which joined the workshop, sixteen teams agreed on joining this research. Hence voice recorders were placed on the table where these sixteen teams worked. Because one voice recorder turned out to be broken, voice records were collected from fifteen teams in the end. Some of the voice records only contains discussion after the second process, which is clarifying the reason why the condition should be true, due to practical reasons. Also, the data of activity in Apisnote were downloaded for these fifteen teams and used in this research. Additionally, interviews to some participants were conducted after the workshop. This research mainly utilized three types of data mentioned above. 


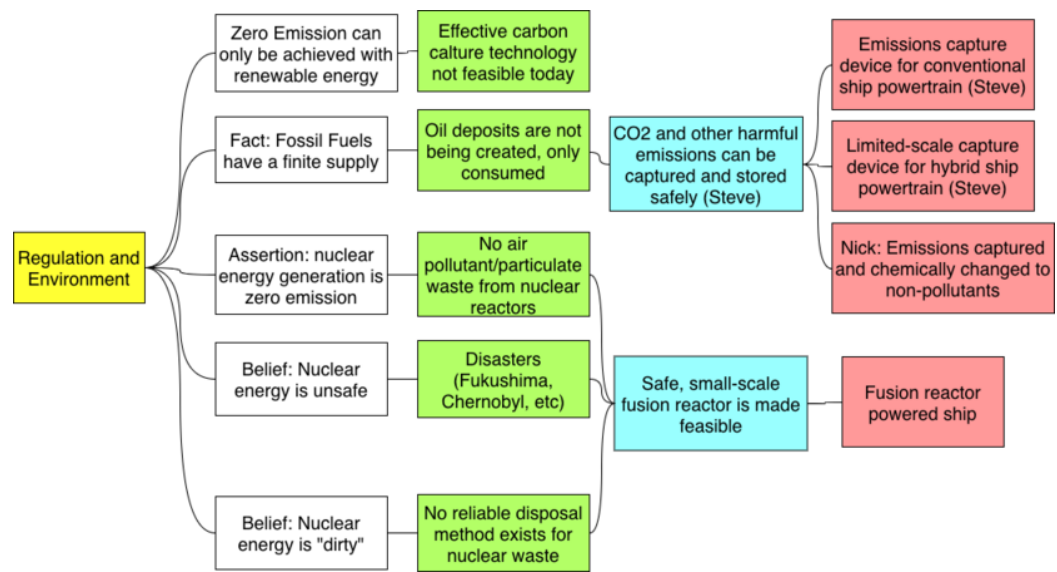

Figure 2. Sample Notes from Bias Breaking to Achieve Zero Emission Shipping.

All of the processes above were conducted with Apisnote, a web application of a shared sticky note. A user can write and post a sentence, and draw a link between each note. Every action of a user is shared in real time to the other users who are using the same worksheet. The contents of the notes were recorded and tagged with an identification number of the participant who created it and the time when it was created. Fig. 3 shows how the result of the work was supposed to be placed.

Instrumentation and Data used a digital platform called ApisNotes, which can apply to ideation workshops of various types. Not only allows collaborative real time usage, but also then records the process of creation, spatial layout, categorization, changes, and associations over time. An example of the interface for Apisnote as used in this workshop is shown in the figure below, and additional exampes for the workshop making approach can be seen in source [18].

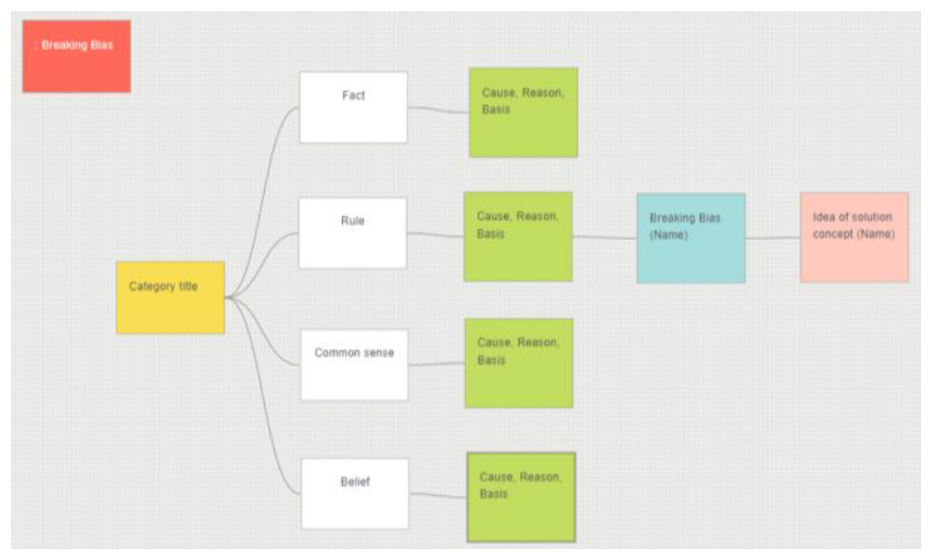

Figure 3. Example Apisnote software as used in Workshop.

Evaluation of "Breaking Bias" notes

- The result of evaluation was summarized in Table 1. One hundred and ninetyeight notes were evaluated in total, and forty-six notes were rated as good notes. 
Table 1 and Figure 4 show the number of good notes and the percentage of good notes respectively.

Table 1. Table Evaluation of "Breaking Bias" notes.

\begin{tabular}{|c|c|c|c|c|}
\hline Team & $\begin{array}{c}\text { Number of } \\
\text { good notes }\end{array}$ & $\begin{array}{c}\text { Number of } \\
\text { bad notes }\end{array}$ & Total & $\begin{array}{c}\text { \% of good } \\
\text { notes }\end{array}$ \\
\hline $\mathbf{1}$ & 6 & 3 & $\mathbf{9}$ & 67 \\
\hline $\mathbf{2}$ & 7 & 8 & $\mathbf{1 5}$ & 47 \\
\hline $\mathbf{3}$ & 1 & 5 & $\mathbf{6}$ & 17 \\
\hline $\mathbf{4}$ & 4 & 13 & $\mathbf{1 7}$ & 24 \\
\hline $\mathbf{5}$ & 0 & 7 & $\mathbf{7}$ & 0 \\
\hline $\mathbf{6}$ & 3 & 12 & $\mathbf{1 5}$ & 20 \\
\hline $\mathbf{7}$ & 0 & 6 & $\mathbf{6}$ & 0 \\
\hline $\mathbf{8}$ & 1 & 9 & $\mathbf{1 0}$ & 10 \\
\hline $\mathbf{9}$ & 3 & 16 & $\mathbf{1 9}$ & 16 \\
\hline $\mathbf{1 0}$ & 10 & 8 & $\mathbf{1 8}$ & 56 \\
\hline $\mathbf{1 1}$ & 0 & 9 & $\mathbf{9}$ & 0 \\
\hline $\mathbf{1 2}$ & 8 & 19 & $\mathbf{2 7}$ & 30 \\
\hline $\mathbf{1 3}$ & 2 & 14 & $\mathbf{1 6}$ & 13 \\
\hline $\mathbf{1 4}$ & 0 & 17 & $\mathbf{1 7}$ & 0 \\
\hline $\mathbf{1 5}$ & 1 & 6 & $\mathbf{7}$ & 14 \\
\hline Total & $\mathbf{4 6}$ & $\mathbf{1 5 2}$ & $\mathbf{1 9 8}$ & $\mathbf{2 3}$ \\
\hline & & & & \\
\hline
\end{tabular}

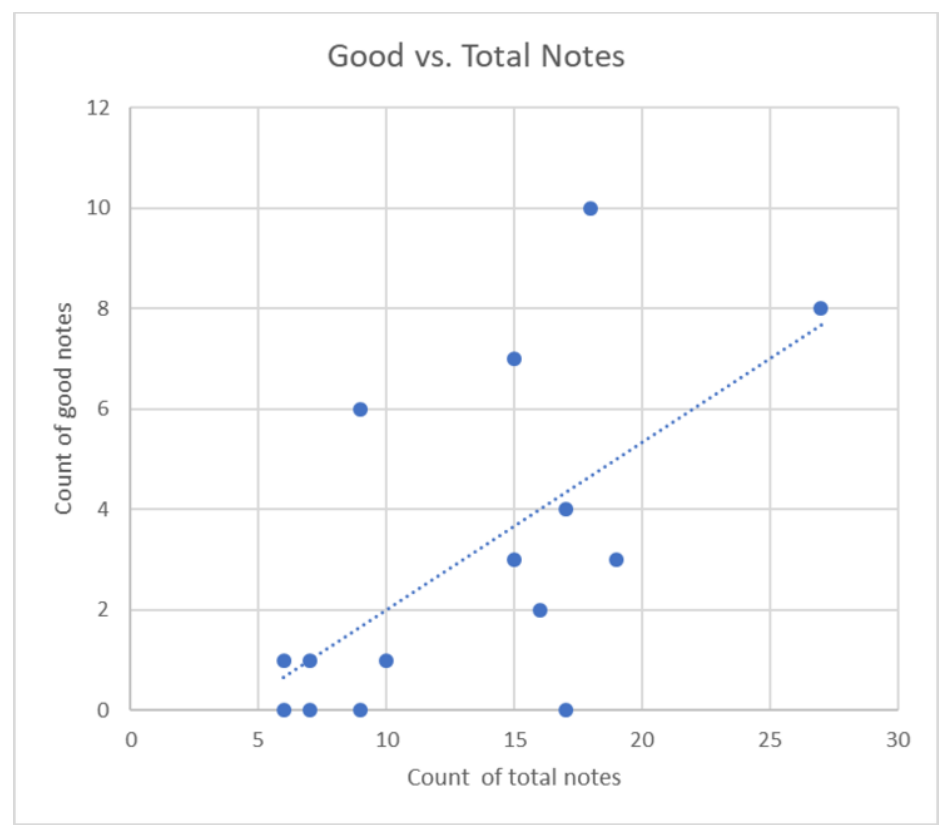

Figure 4. Trend of Good Notes to Total Count for each of 15 teams. 


\section{Analysis of notes about conditions}

By categorizing every note based on the similarity of the content, seven categories and twenty-seven subcategories were created. Tables 2 and 3 show categories and subcategories, and the number of notes which was allocated to each subcategory.

Table 2. Number of Notes by Sub Category.

\begin{tabular}{|c|c|c|}
\hline Category name & Sub-category name & Number of notes \\
\hline \multirow[t]{4}{*}{ Renewable energy } & General renewable energy & 12 \\
\hline & Solar or wind & 12 \\
\hline & Nuclear power & 5 \\
\hline & Other renewable energy & 8 \\
\hline \multirow[t]{4}{*}{ Conventional energy } & Coal & 4 \\
\hline & Fossil Fuels & 6 \\
\hline & Batteries & 4 \\
\hline & Diesel & 1 \\
\hline \multirow[t]{3}{*}{ Zero emission } & Definition or needs of zero emission ship & 13 \\
\hline & Technology for zero emission & 10 \\
\hline & Impact of zero emission & 17 \\
\hline \multirow[t]{4}{*}{$\mathrm{CO2}$} & Dealing with $\mathrm{CO} 2$ & 3 \\
\hline & Current state or future projection about $\mathrm{CO} 2$ & 25 \\
\hline & Reduction of $\mathrm{CO} 2$ & 12 \\
\hline & Effect of $\mathrm{CO} 2$ & 3 \\
\hline \multirow[t]{5}{*}{ Ship system } & Hull & 20 \\
\hline & Operation & 14 \\
\hline & Propulsion system & 10 \\
\hline & Power & 7 \\
\hline & Infrastructure & 2 \\
\hline Ship business & Company & 26 \\
\hline \multirow[t]{6}{*}{ Macro or general topic } & Shipping industry & 42 \\
\hline & Public opinion & 15 \\
\hline & Policy or rule & 16 \\
\hline & Economy & 2 \\
\hline & Technology & 13 \\
\hline & Nature & 4 \\
\hline
\end{tabular}

Table 3. The number of notes in each category for each team.

\begin{tabular}{|c|c|c|c|c|c|c|c|c|c|c|c|c|c|c|c|c|}
\hline \multicolumn{1}{|c|}{ Team } & $\mathbf{1}$ & $\mathbf{2}$ & $\mathbf{3}$ & $\mathbf{4}$ & $\mathbf{5}$ & $\mathbf{6}$ & $\mathbf{7}$ & $\mathbf{8}$ & $\mathbf{9}$ & $\mathbf{1 0}$ & $\mathbf{1 1}$ & $\mathbf{1 2}$ & $\mathbf{1 3}$ & $\mathbf{1 4}$ & $\mathbf{1 5}$ & Total \\
\hline Renewable energy & 2 & 5 & 2 & 1 & 3 & 2 & 4 & 1 & 1 & 2 & 2 & 4 & 1 & 3 & 4 & $\mathbf{3 7}$ \\
\hline Conventional energy & 2 & 3 & & 1 & 1 & 1 & & & 1 & 1 & & 2 & 2 & & 1 & $\mathbf{1 5}$ \\
\hline Zero emission & 2 & & 2 & 3 & 4 & & 3 & & 10 & 3 & 2 & & 4 & 1 & 6 & $\mathbf{4 0}$ \\
\hline CO2 & 2 & & 4 & 5 & & & 1 & 3 & 8 & 1 & 3 & 7 & 3 & 4 & 2 & $\mathbf{4 3}$ \\
\hline Ship system & 7 & 7 & 1 & 3 & & 10 & 2 & & 1 & 5 & 2 & 12 & & 2 & 1 & $\mathbf{5 3}$ \\
\hline Ship business & & & 3 & 2 & & 1 & 3 & 2 & 4 & 1 & 2 & 1 & 2 & 3 & 2 & $\mathbf{2 6}$ \\
\hline Macro or general topic & 9 & 1 & 9 & 8 & 1 & 4 & 8 & 7 & 4 & 2 & 9 & 6 & 6 & 6 & 12 & $\mathbf{9 2}$ \\
\hline Total & $\mathbf{2 4}$ & $\mathbf{1 6}$ & $\mathbf{2 1}$ & $\mathbf{2 3}$ & $\mathbf{9}$ & $\mathbf{1 8}$ & $\mathbf{2 1}$ & $\mathbf{1 3}$ & $\mathbf{2 9}$ & $\mathbf{1 5}$ & $\mathbf{2 0}$ & $\mathbf{3 2}$ & $\mathbf{1 8}$ & $\mathbf{1 9}$ & $\mathbf{2 8}$ & $\mathbf{3 0 6}$ \\
\hline
\end{tabular}


For each category, the relationship between the number of notes and the performance of the teams was analyzed. Table 4 shows the result of Pearson's correlation analysis. The number of notes about Conventional Resources and Ship System were strongly correlated with the number of good Bias Breaking notes.

Table 4. Correlation of Ideation Topics to higher quality bias breaking notes.

\begin{tabular}{ccc}
\hline Category name & Correlation coefficient & P-Value \\
\hline Renewable energy & 0.1267 & 0.6527 \\
Conventional energy & 0.6623 & 0.0071 \\
Zero emission & -0.1845 & 0.5104 \\
CO2 & 0.0460 & 0.8708 \\
Ship system & 0.6973 & 0.0038 \\
Ship business & -0.4967 & 0.0596 \\
Macro or general topic & -0.3878 & 0.1532 \\
\hline
\end{tabular}

\section{Exploration about the reason for creating important conditions.}

In the process of creating conditions, teams listened to presentation by people who had engaged in a project to create an idea to achieve Zero Emission Shipping. Hence, conditions are possible to come from the presentation slide. However, few conditions which were categorized in Conventional Resources or Ship System were written in the presentation slide. Thus, successful teams created conditions by their own and generated good Breaking Bias notes from them. To identify how they could create conditions by their own, interview will be conducted to members of both successful and unsuccessful teams. The result of interview will reveal the characteristics of teams or members which lead to the success of teams.

\section{Discussion}

This research clarified the correlation between the number of appropriate bias breaking and the type of conditions which groups listed up in an idea creation workshop using bias breaking. Because there were little research that tried to explain factors influencing group performance in idea creation workshops using bias breaking method, creating promising hypothesis is still a crucial step for further investigation. Through this research, several information are found to be important to create hypothesis and prove it. First, to clarify actual process of creating conditions, voice and video data of the first process should be recorded. These data will provide the information such as whether the group listed up conditions individually or by group discussion, what materials group members used for reference, and how these behaviors changed over time. Second, information about participants should also be collected to explain the reason why each team took different process. Examples of valuable information would be professional background like an engineer, manager, leadership experience, or team building experience, personality such 
as extrovert or introvert, and cultural background. These data should be collected the next time when a similar workshop is conducted, to obtain meaningful implications.

\section{Acknowledgements}

The authors would lke to thank our colleagues on the Japan Social Innovation Center and the Global Teamwork Lab for their help, as well as the MIT System Design and Management community for their participation.

\section{References}

[1] B.R. Moser and R.T. Wood, Complex Engineering Programs as Sociotechnical Systems. In J. Stjepandic, N. Wognum, W.J.C. Verhagen (eds.) Concurrent Engineering in the 21st Century: Foundations, developments and challenges, Springer International Publishing Switzerland, 2015, pp. 51-65.

[2] Bias. In Merriam-Webster.Com. Miriam Webster. 2019, Retrieved from https://www.merriamwebster.com/dictionary/hacker, accessed July, 82019.

[3] D.G. Jansson and S.M. Smith, Design fixation. Design Studies, 1991, Vol. 12, No. 1, pp. 3-11.

[4] S.M. Smith, D.R. Gerkens and G. Angello, Alternating incubation effects in the generation of category exemplars. The Journal of Creative Behavior, 2017, Vol. 51, No. 2, pp. 95-106.

[5] E.G. Chrysikou and R.W. Weisberg, Following the wrong footsteps: Fixation effects of pictorial examples in a design problem-solving task. Journal of Experimental Psychology: Learning, Memory, and Cognition, 2005, Vol. 31, No. 5, 1134.

[6] R.L. Marsh, T.B. Ward and J.D. Landau, The inadvertent use of prior knowledge in a generative cognitive task. Memory \& Cognition, 1999, Vol. 27, No. 1, pp. 94-105.

[7] S.M. Smith and J. Linsey, A three-pronged approach for overcoming design fixation. The Journal of Creative Behavior, 2011, Vol. 45, No. 2, pp. 83-91.

[8] A. Purcell, P. Williams, J. Gero and B. Colbron, Fixation effects: Do they exist in design problem solving? Environment and Planning B: Planning and Design, 1993, Vol. 20, No. 3, pp. 333-345.

[9] L. Pelegrin, B.R. Moser and V. Sakhrani, Exposing Attention-Decision-Learning Cycles in Engineering Project Teams through Collaborative Design Experiments. Proceedings of the 52nd Hawaii International Conference on System Sciences, 2019, http://hdl.handle.net/10125/59475, accessed July, 82019.

[10] N. Wognum, C. Bil, F. Elgh, M. Peruzzini, J. Stjepandić and W.J.C Verhagen, Transdisciplinary systems engineering: implications, challenges and research agenda, International Journal of Agile Systems and Management, Vol. 12, 2019, No. 1, pp. 58-89.

[11] E. Kim and H. Horii, A study on an assessment framework for the novelty of ideas generated by analogical thinking. Procedia-Social and Behavioral Sciences, 2015, Vol. 195, pp. 1396-1406.

[12] C. Fruehling and B.R. Moser, Analyzing Awareness, Decision, and Outcome Sequences of Project Design Groups: A Platform for Instrumentation of Workshop-Based Experiments. In E. Bonjour, D. Krob, L. Palladino and F. Stephan (eds.), Complex Systems Design \& Management, Springer International Publishing Switzerland, 2019, pp. 179-191.

[13] M. Iluz, B.R. Moser, and A. Shtub, Shared Awareness among Project Team Members through Rolebased Simulation during Planning-A Comparative Study, Procedia Computer Science, 2015, Vol. 44, pp. 295-304.

[14] B.R. Moser, W. Grossmann and P. Starke, Mechanisms of Dependence in Engineering Projects as Sociotechnical Systems, Advances in Transdisciplinary Engineering, Vol 2: Transdisciplinary Lifecycle Analysis of Systems, IOS Press, Amsterdam, 2015, pp. 142-151.

[15] P.S. Tan and B.R. Moser, Detection of Teamwork Behavior as Meaningful Exploration of Tradespace During Project Design. In M.A. Cardin, D. Hastings, P. Jackson, D. Krob, P.C. Lui, G. Schmitt (eds.) Complex Systems Design \& Management Asia, Springer International Publishing, 2018, pp. 73-87.

[16] S.I. IMO, GHG Study 2009, International Maritime Organization, London, 2009.

[17] M. Traut, A. Larkin, K. Anderson, C. McGlade, M. Sharmina and T. Smith, CO2 abatement goals for international shipping. Climate Policy, 2018, Vol. 18, No. 8, pp. 1066-1075.

[18] E. Kim and H. Horii, Designing the Workshop Process for Generating Innovative Ideas: Theoretical and Empirical Approach. Business and Management Studies, 2016, Vol. 2, No. 4, pp. 30-41. 